\title{
Introduction: The Varieties of Enactivism
}

\author{
Dave Ward $^{1} \cdot$ David Silverman $^{2} \cdot$ Mario Villalobos $^{3,4}$
}

Published online: 18 April 2017

(C) Springer Science+Business Media Dordrecht 2017

Just over 25 years ago, Francisco Varela, Evan Thompson and Eleanor Rosch published The Embodied Mind: Cognitive Science and Human Experience (TEM). An ambitious synthesis of ideas from phenomenology, cognitive science, evolutionary biology, Buddhist philosophy and psychology, it attempted to articulate a new research programme: an enactive cognitive science, that would bridge the gap between the empirical study of the mind and the disciplined reflection on our lived experience that characterises phenomenological and Buddhist practices. This enactive approach to the study of mind represented a confluence of several streams of thought whose effect on the cognitive scientific landscape was becoming gradually more pronounced. A vision of cognition as active, embodied, and embedded was beginning to crystalise, and TEM consolidated and further strengthened existing trends. In the intervening years, the theoretical currents that flowed into TEM have only grown stronger within cognitive science and philosophy of mind. As a result, the 'enactivist' label has gained in currency, as different combinations of TEM's main conceptual ingredients have been concocted and presented by different researchers. A consequence of this is the apparent existence of a variety of distinct but overlapping 'enactivisms', the relations between which are not always clear. This special issue aims to provide a clearer picture of the enactivist theoretical landscape, some of its distinctive

Dave Ward

dave.ward@ed.ac.uk

1 University of Edinburgh, Edinburgh, UK

2 Université Paris Descartes, Paris, France

3 Universidad de Tarapacá, Arica, Chile

4 Instituto de Filosofía y Ciencias de la Complejidad, Santiago, Chile landmarks, and the disputed borders between its main provinces. Each of the papers in this issue takes up and pursues a live theoretical issue for enactivist research, while at the same time shedding light on the conceptual geography of enactivism. In this introduction, we frame these contributions by providing a brief sketch of the streams of thought that flowed into TEM and the origins of enactivism, and the main theoretical channels that have emerged from it.

\section{Ancestors}

Potted histories of any subject area-especially one as young as cognitive science-are inevitably partial and biased. Nonetheless, considering how a relevant chunk of intellectual history appears from a particular perspective helps in understanding that perspective and its motivations. The following account of the recent history of cognitive science from the perspective of enactivism thus makes no claims to completeness or objectivity. However, as we will see, understanding the ways in which different groups of theorists have combined the ingredients below is helpful in understanding the varieties of enactivism.

Work on TEM began in the mid-80s, against the backdrop of the then-dominant cognitivist paradigm in cognitive science. ${ }^{1}$ Cognitivism attempted to understand intelligence in terms of the production, transformation and manipulation of inner states that represented properties of the domain that the cognizer was trying to deal with. Its guiding image was the mind as computer. From the

\footnotetext{
1 See the introduction to, and the papers collected in Haugeland (ed.) (1981) for an overview of classical cognitivism, some of its theoretical highlights, and its early challenges. See Thompson (2004) for an account of the origins of TEM.
} 
mid-twentieth century, the cleverest objects whose workings we could understand were computers-systems that took in impoverished inputs from their environment (via key-presses or other simple sensors), went through a complex sequence of structured inner states whose unfolding was governed by well-specified algorithms and principles, and produced some output appropriate to the task for which it had been programmed. We humans can also do some pretty clever things, and we know that a staggeringly complex web of internal states intervenes between our perception of the environment and our intelligent response to it. Understanding our cognitive capacities as those of particularly fancy, biologically realised, computational systems seemed (and still seems) like a good bet.

However, despite its theoretical fertility and impressive array of early successes, the cognitivist paradigm faced problems. Cognitivists struggled to model or explain the flexible, context-sensitive and domain-general intelligence that is characteristic of human cognition. Intuitively basic cognitive capacities like motor control and perceptual recognition seemed particularly resistant to cognitivist efforts. And, among philosophers, there was a lack of theoretical consensus over the best account of the notion of 'representation' at the heart of cognitivism. By the time of the publication of TEM the challenges faced by the cognitivist view were beginning to look more like permanent and insuperable obstacles than the teething problems of a new paradigm. At the same time, several apparently distinct strands of cognitive-scientific theorising were yielding models, explanations and results that looked at odds with the cognitivist framework.

Work on connectionist neural networks ${ }^{2}$ suggested that computational explanations of intelligent behaviour needn't appeal to the serial production and manipulation of discrete representational states; instead, adaptive behaviour can emerge out of a the activity of a densely interconnected web of interacting units. Importantly, the patterns of connectivity that specify the structure of a connectionist network need not be rigid or pre-specified. Instead, connectionist networks can be self-organising systems; the structure that underlies their intelligent behaviour can emerge as a result of a network's learning and interactive history. Connectionist models had notable success with domains that troubled cognitivists, such as pattern recognition and sensorimotor control. A closely related emerging

\footnotetext{
${ }^{2}$ See Clark $(1989,1993)$ for surveys of connectionism's origins and early successes, and its contrasts with cognitivism.
}

theme was the use of tools from dynamical systems theory (DST) in characterising cognitive organisation. ${ }^{3}$ DST provides formal and conceptual apparatus for describing the unfolding operations of complex systems composed of multiple closely interacting parts-including self-organising systems like (some) connectionist networks. The language of DST characterises systems in terms of a multidimensional space of possible states the system can be in, equations that describe the ways in which the system can transition from one point in state space to another, and theoretically significant points in that space such as attractors-stable states to which a system's activity will often tend. Of special relevance to the historical narrative we're constructing here is the fact that these characterisations eschew talk of discrete, static representations in favour of a global description of the state of a system and its activity.

At the same time as these trends, work in the tradition of ecological psychology suggested a complementary set of reactions to cognitivism. ${ }^{4}$ According to Gibson's (1979) ecological psychology, visual perception of the environment is direct in that it should not be understood in terms of representational or computational states that reconstruct environmental information that is lost in sensory transduction. Part of the reason that such states are not required is that perception is active in at least two ways. First, since the environment's sensory effects on us unfold over time, and can be modulated by our own activity (squinting, looking more closely, moving around), a conception of visual perception as the recovery of detailed information from a static and impoverished perceptual stimulus underestimates the resources available to our perceptual systems. Second, what we perceive is tied to our purposes and capacities. We perceive affordances - opportunities to engage with the environment in ways that reflect our needs and plans-rather than practically neutral information that our perceptual systems must interpret and put in touch with our capacities for action. Finally, this active, direct conception of perception goes along with a conception of perceiver and environment as a co-defined and co-dependent. A perceiver's

\footnotetext{
${ }^{3}$ See e.g. Horgan and Tienson (1992) for an early statement of the relevance of dynamical systems theory for philosophy of cognitive science, and Clark (1997) for a philosophical survey and critical assessment of dynamical systems approaches to cognition.

${ }^{4}$ See Gibson (1979) for the locus classicus of ecological psychology, and Chemero (2011) for a contemporary summary and defense. We don't mean to suggest here that Gibsonian psychology was a central inspiration of TEM itself-Varela, Thompson and Rosch (1991, pp. 202-203) take care to point out the differences between their view and Gibson's (1979). Varela's earlier work with Maturana (e.g. Maturana and Varela 1980; see also Varela 1997) and the phenomenological currents discussed below are more important theoretical antecedents of the relational view of cognition developed in TEM.
} 
environment is just that set of features which can perceptually guide its ongoing activities. And to be a perceiver is to be the sort of creature that can be so guided by the environment.

A final related area of empirical enquiry that was gaining momentum during the gestation of TEM was work on situated robotics. ${ }^{5}$ As noted above, successful cognitivist models often exhibited only brittle and domain-specific capacities for intelligent response, and struggled in particular with adaptive sensorimotor control. MIT roboticist Rodney Brooks noted that these limitations were also reflected in cognitivist $\mathrm{AI}$, with the most sophisticated extant robots failing to approximate the ecologically robust sensorimotor intelligence of simple insects. Setting out to remedy this, Brooks (1991) engineered and built a series of robots (or 'Creatures') designed to flexibly produce a range of simple adaptive behaviours in interaction with real environments. Instead of designing according to cognitivist principleswith behaviour guided by producing and continuously updating detailed representations of the target environment-Brooks' robots consisted of a number of special purpose subsystems, most of which guided a simple sensorimotor behaviour. Rather than having each subsystem feed in to a central processor that would calculate and command a single course of action for the robot, the subsystems were interconnected such that the activity of each one could inhibit the activity of others, in ways that could be easily tweaked and manipulated by the engineers. Thus, summarises Brooks:

Just as there is no central representation there is not even a central system. Each activity producing layer connects perception to action directly. It is only the observer of the Creature who imputes a central representation or central control. The Creature itself has none; it is a collection of competing behaviors. Out of the local chaos of their interactions there emerges, in the eye of an observer, a coherent pattern of behavior. (1991, pp. 148-149)

Brooks' Creatures could indeed produce coherent, adaptive behaviours. Most famously, 'Herbert' (named after cogsci pioneer and polymath Herb Simon) could trundle around the MIT labs, scanning surfaces for empty coke cans, which it would pick up and transport to a bin. Brooks' Creatures provided an existence proof that simple modes of intelligence could be engineered by way of multiple interacting sensorimotor capacities, without recourse to a detailed model of the environment as a locus of central

\footnotetext{
5 The classic example is Brooks (1991). Brooks' work is discussed as an illustrative case of enactive cognitive science in TEM pp. 207212. See Pfeifer and Bongard (2006) for a more recent overview.
}

control. Instead, Brooks designed his Creatures to use the world as its own best model, emphasising the capacity to quickly and reliably access behaviourally-relevant information in the world over the capacity to reconstruct that information internally.

Lastly, the split between proponents of cognitivism and those tempted by the alternative research programmes sketched above appeared symptomatic of deeper philosophical divisions. The theoretical appeal of cognitivism can partly be traced back to Frege's demonstration that a broad class of logical inferences-the sorts of things that minds appear to traffic in - can be specified in terms of formal rules for manipulating syntactical structures, and Turing's demonstration that any set of such rules can be implemented and followed by a machine. Against this backdrop, cognitivists could busy themselves identifying the relevant syntactic structures, the rules for manipulating them, and the engineering principles according to which these structures and rules were implemented in the human brain. The origins of cognitivism thus overlap with those of a central strand of 'analytic philosophy' - the construal of thought in terms of formal transitions between propositions, and the construal of minds as fundamentally seats of propositional attitudes. The work of several Phenomenologists, however, suggested an alternative to this background conception of mindedness. ${ }^{6}$ For example, Heidegger (1927/1962) is often read as arguing that a thinker's capacity to explicitly represent elements of her environment (as in a propositional attitude) depends on a prior capacity to skilfully interact with the environment in ways that are already subject to normative constraints. The capacity to think of a hammer as too heavy for this particular job depends on a prior capacity to hammer, and a prior sense of what it's like for hammering to be going well or badly. Merleau-Ponty (1945/2012) likewise argues that the capacity to stand in a meaningful cognitive relationship to the environment depends on a suite of capacities for bodily interaction, with this dependence resulting in the particular details of our embodiment making crucial contributions to the structure of thought and experience. Hubert Dreyfus $(1972,2007)$ argued influentially that cognitivism's limits had been accurately predicted by phenomenological critiques of empiricist and rationalist psychology, and these remarks looked increasingly prescient as cognitivism struggled to model the kinds

\footnotetext{
6 The two most influential works in this connection are Heidegger (1927/1962) and Merleau-Ponty (1945/2012). See Dreyfus (1972, 2007) and Haugeland (1978, 2013) for canonical applications of arguments from these sources to cognitive science. See Kaufer and Chemero (2015) and Gallagher and Zahavi (2013) for recent overviews of the relationship between phenomenology and cognitive science.
} 
of flexible, active and engaged intelligence emphasised by Phenomenologists.

All these ideas were in the air while the first enactivist manifesto was being developed. Against cognitivism's explanatory emphasis on the construction and manipulation of representations that were discrete and internal, each of these trends emphasised in different ways the explanatory power of interaction with the cognizer's environment, and the importance of external or implementational factors. As we've seen, these can include properties of the cognizer's body, its environment, or the dynamics of the interactions between these factors.

\section{The Embodied Mind}

The enactive approach introduced in The Embodied Mind drew on each of the above strands in varying degrees, and outlined a unifying explanatory framework that combined them with concepts from systems biology and Buddhist practices. In an initial definition of enactivism, the authors tell us:

In a nutshell, the enactive approach consists of two points: (1) perception consists in perceptually guided action and (2) cognitive structures emerge from the recurrent sensorimotor patterns that allow action to be perceptually guided. (TEM, p. 173)

For the purposes of understanding TEM's enactivism, this second point takes priority. For cognitivism, as sketched above, the cognitive structures of interest are internal states which represent determinate properties of the environment that are absent or imperfectly accessed. Enactivism instead emphasises emergent cognitive structures that self-organise as a result of interactions between organism and environment. The clearest and best-known example of this doesn't feature in TEM, but is a key ingredient of enactivism's conceptual history. Consider the organisation of a single cell bacterium (Varela 1997). The bacterium is separated from the molecular soup that surrounds it by a semi-permeable boundary that is both created and maintained by a network of processes (absorbing nutrients, expelling waste products) that criss-cross the organism/environment boundary. The bacterium is thus an autopoietic system-one that 'generates and specifies its own organization through its operation as a system of production of its own components' (Maturana and Varela 1980 , p. 79). In this way, a biological unity emerges from a nexus of interactions with portions of its environment. The details of these interactions-their distinctive dynamicsmatters, especially insofar as they bear on the particular way in which the organism is embodied. This is because details of an organism's embodiment determine structures and properties in the environment that bear on the organism's flourishing. In the case of bacteria, for example:

although sucrose is a real and present condition of the physicochemical environment, its status as food is not. That sucrose is a nutrient is not intrinsic to the status of the sucrose molecule; it is, rather a relational feature, linked to the bacterium's metabolism. Sucrose has significance or value as food, but only in the milieu that the organism itself brings into existence. (Thompson 2007, p. 158)

The enactive approach outlined in TEM thus entails that both the organism and the meaningful structures in its environment emerge from a set of self-organising dynamic processes. These environmental structures are meaningful insofar as they bear on the organism's success or failure in keeping itself around as an autopoietic unity, and in that sense have significance for the organism's existence. And it is in virtue of this significance that the enactivist counts the structures brought about by such interactions as $\operatorname{cog}$ nitive. Whereas the cognitivist holds that significance (or meaning) is bestowed by the organism representing environmental structures in the service of adaptive behaviour, TEM argues that significance is enacted as part of a dynamical process that creates and sustains both the organism and the environment to which it is responding-the adaptive behaviour emerges from, and is sustained by, a set of dynamic interactions that itself gives rise to the organism/ environment distinction.

It is this view of the co-production of cognizer and environment through dynamic interaction that accounts for TEM's view of perception as perceptually guided action. Varela, Thompson and Rosch claim Brooks' Creatures as an illustrative example of enactive cognitive science (TEM pp. 207-212) in virtue of Brooks' emphasis on coupled environmental interaction over the construction of detailed internal representations. Likewise, the affinities between TEM's enactivism and Gibson's ecological approach are clear-there is both a shared emphasis on organism and environment as co-dependent, and on the organism's capacity for direct interaction with structures that bear on the success of its activities. ${ }^{7}$ For Gibson, perception is not a process of passive reception of information that is built up

\footnotetext{
7 In TEM (pp. 203-204) the authors distinguish their position from Gibson's by arguing that Gibson understands environmental structures as objective, pre-specified properties to which the organism must respond, in contrast to enactivism's emphasis on organism and environmental properties as simultaneously enacted. Adjudicating this dispute would take us too far into Gibson-exegesis for our purposes here-but the claim that TEM places greater emphasis on organism/environment co-dependence than Gibson looks wellfounded. Likewise, TEM goes beyond Gibson in its particular conception of the interactive dynamics underlying this co-dependence.
} 
into a representation of a meaningful environment, but direct sensitivity—often made possible by exploratory activity-to properties of the environment that are already action-relevant. TEM agrees with this Gibsonian picture, but adds a specific vision of the coupled relationship that makes such direct perception possible. As we'll see below, the link between perception and perceptually-guided action is taken up in various ways by subsequent enactivist theorists.

TEM's emphasis on engaged activity over detached representation, and the way in which details of embodiment determine details of cognitive relations to the environment, are two points of contact with the Phenomenological tradition sketched above. Another is its rejection of a strictly realist or objectivist conception of the world to which we respond in perception, in favour of a conception of the world as both a product and reflection of our engaged activity. The agenda of TEM is announced at the outset as 'a modern continuation of a programme of research founded over a generation ago by the French philosopher, Maurice Merleau-Ponty' (p. xv), and follows Merleau-Ponty in aiming for a middle ground between realist and idealist conceptions of the relationship between mind and world. However, TEM also expresses scepticism about the scope of phenomenological philosophy, worrying that it consists in detached post-hoc theorising that might distort the experiences it aims to analyse. In response, TEM argues that Buddhist meditation and mindfulness practices should be integrated into an enactive cognitive science: 'mindfulness techniques are designed to lead the mind back from its theories and preoccupations, back from the abstract attitude, to the situation of one's experience itself' (p. 22). Much of TEM consists in putting insights from Buddhist traditions into contact with the conceptual apparatus and analyses of enactivism. ${ }^{8}$

All this allows us to see why Varela, Thompson and Rosch begin TEM by saying:

This book begins and ends with the conviction that the new sciences of mind need to enlarge their horizon to encompass both lived human experience and the possibilities for transformation inherent in human experience. Ordinary, everyday experience, on the other hand, must enlarge its horizon to benefit from the insights and analyses that are distinctly wrought by the sciences of mind. (p.xv)

\footnotetext{
8 Whilst the interaction between enactivism and Buddhist practices has not been an influential theme in the other varieties of enactivism we will survey here, it continues to be reflected in Evan Thompson's recent work (e.g. 2014). See Thompson's Preface to the new edition of TEM for some important qualifications about his current attitude to the relationship between Phenomenological and Buddhist traditions.
}

Enactivism's mission, as outlined in $T E M$, is to explore the ways in which cognitive science and human experience reciprocally inform each other. The authors' key claim is that the various cognitive scientific trends surveyed above and synthesised in TEM support a vision of mind as emergent, embodied and engaged that was glimpsed by phenomenologists such as Merleau-Ponty, and articulated and made central in many Buddhist traditions. This convergence should encourage us to prefer enactivist cognitive science to its cognitivist precursors, and to transform our self-understanding through engaging in mindfulness practices that corroborate these discoveries.

\section{Descendents}

Since TEM's publication there have been at least three semi-distinct currents of enactivist theorising. First, what is sometimes called autopoietic enactivism, which emphasises TEM's project of grounding cognition in the biodynamics of living systems; second, sensorimotor enactivism, which focuses on analysing the structure, content and character of perceptual experience in terms of the relationships between sensation and embodied activity; third, radical enactivism, which focuses on the case for rejecting representationalist explanations of cognitive capacities in favour of explanatory strategies emphasising patterns of embodied interaction. Finally, enactivist theorising overlaps with various attempts to understand minds as embodied, embedded, extended and affective that draw on the traditions sketched in Sect. 1, while rejecting or remaining neutral on particular enactivist tenets.

\subsection{Autopoietic Enactivism}

Perhaps surprisingly, the term 'autopoeisis' is not mentioned in TEM. Instead, the closely related notion of autonomy is emphasised - the way in which the self-sustaining biodynamics of autopoietic systems create both a distinction between an organism and its environment, and a domain of interactions that bear on the organism's prospects for survival. The 'autopoietic' strand of enactivist theorising emphasises and develops this attempt to ground cognition in the biodynamics of living systems. ${ }^{9}$ In holding

\footnotetext{
9 Key works include Varela (1997), Weber and Varela (2002), Di Paolo (2005), Thompson (2007). Given the fact that TEM emphasises autonomous rather than autopoietic organisation, 'Autopoietic enactivism' is perhaps an imperfect term for this branch of enactivist theory. Nonetheless, labelling forms of enactivism that emphasise biodynamics in this way has become commonplace (see e.g. Degenaar and O'Regan, Hutto and Wheeler's contributions to this issue; see Barandiaran's contribution for a reconstruction of enactivism emphasising autonomy).
} 
that cognition is grounded in the dynamics of biological life itself, autopoietic enactivists incur a commitment to the strong continuity of life and mind - the view that the organisational structures and principles distinctive of mind are simply enriched versions of the structures and principles grounding life itself. As we saw above, autopoietic enactivists hold that simple sensorimotor interactions between organism and environment bring with them a form of teleological directedness to the environment (as when the bacterium's activity aims at the sucrose-rich portions of its environment) and significance or value in the organism's environment (as when the chemical composition of the bacterium's environment becomes good for the bacterium in virtue of the dynamics of its embodiment). This process of enacting cognitive structures is sometimes called sensemaking by autopoietic enactivists. ${ }^{10}$

One source of difference within autopoietic enactivist views is the particular conception of the biodynamics required for cognitive organisation. Whereas TEM emphasises the dynamics of autonomy, Di Paolo (2005) influentially proposed that genuine cognition requires a capacity on the part of the organism to actively modify its relationship to the environment in ways that help it to persist as an autopoietic unity (as when, for example, the bacterium moves its flagella in a way that propels it towards the sucrose-rich area). Both this capacity, and the dynamics through which it is realised, are called adaptivity by $\mathrm{Di}$ Paolo and subsequent enactivists. Barandiaran's contribution to this issue takes up this debate, arguing that autonomous organisation is the mark of cognitive systems, and offering an improved conception of autonomy that makes its foundational role clear, and is complemented by ongoing work in simulated robotics.

Another distinctive feature of much contemporary autopoietic enactivism is the way in which the deep continuity of life and mind is argued for. Whereas TEM implies that the dynamics of autonomous organisation straightforwardly entail a teleological relationship between organism and environment that marks the beginnings of mindedness, Weber and Varela (2002) argue that the continuity of life and mind is first and foremost phenomenologically evident to us, and that this phenomenological evidence is what ultimately grounds the enactivist attempt to explain cognition in terms of biodynamics. In this they are partly inspired by the phenomenologist Hans Jonas (1966) and his dictum that 'life can only be known by life'. In line with TEM, Jonas understood the dynamics of metabolic processes as bringing about autonomous entities that stood in teleological relations to their environments. But, in considering how

10 See in particular Weber and Varela (2002), Thompson and Stapleton (2009) and Di Paolo and Thompson (2014). a teleological relationship can be inferred from metabolic dynamics, Jonas asks:

But what kind of inference is this? And by whom? How can the unprepared observer infer what no mere analysis of the physical record will ever yield? The unprepared observer cannot... The observer of life must be prepared by life. In other words, organic existence with its own experience is required of himself for his being able to make that inference. (Jonas 1966, p. 82)

This 'Jonasian inference' from our own lived experience to the deep continuity of life and mind plays an important role in much contemporary autopoietic enactivism. ${ }^{11}$ Barrett's contribution to this special issue critically examines the way in which normative concepts like concern and flourishing have been introduced into autopoietic enactivism, arguing that the various kinds of organisational dynamics in which enactivists attempt to ground the normative properties of cognition entail only proscriptive normativity-they can constitute a system that backs away from danger or instability, but not one that seeks self-preservation, or positively values its surroundings. Barrett's argument poses serious problems for many contemporary autopoietic enactivists, who view (prescriptive) concern and care for one's well-being as a fundamental property of cognition.

Autopoietic enactivism, then, takes up the general project outlined in TEM and pursues it with a particular emphasis on the way in which cognitive structures emerge from interactive dynamics. Its most canonical instances supplement the Merleau-Pontian phenomenological inspiration of TEM with ideas from Hans Jonas's phenomenology of life, and its associated deep continuity of life and mind.

\subsection{Sensorimotor Enactivism}

Sensorimotor enactivism is usually presented as a way of explaining the intentional and phenomenal characteristics of perceptual experience rather than a general account of the mind. ${ }^{12}$ It shares with TEM a conception of perception as an active exploration of the environment rather than the construction of an inner model that recovers information lost in sensory transduction, and thus shares Merleau-Pontian, Gibsonian and Brooksian roots with TEM and

\footnotetext{
11 See Villalobos and Ward (2016), Ward and Villalobos (2016) for critical discussion of the role of the 'Jonasian inference' in enactivist theorising.

12 Key works in this camp include Hurley (1998), O'Regan and Noë (2001), Noë (2004, 2012), O’Regan (2011).
} 
autopoietic enactivism. However, sensorimotor enactivism largely ignores or downplays the other theoretical principles associated with enactivism, such as the co-production of organism and environment, emphases on biodynamics and a commitment to life/mind continuity.

Sensorimotor enactivists propose to account for the content and character of perception by appealing to sensorimotor contingencies: patterns of dependence obtaining between perception and exploratory activity. One way of motivating sensorimotor enactivism is by reflecting on the limits of our visual sensitivity, such as the low fidelity of parafoveal vision, the blind spot in our visual field, and the fact that we can only see some of the parts of an object at a time. In addition, experiments on change and inattentional blindness (discussed in O'Regan and Noe 2001) appear to show that the brain does not explicitly model rich and uniform detail. Yet our visual experience is of a rich and continuous world of complete objects. How is this possible? Sensorimotor enactivists answer this question by appealing to two related facts that were also emphasised by MerleauPonty and Gibson. First, that perception is a process that unfolds over time, and second, that a mobile perceiver has some control over the way in which sensory stimulation unfolds. How can I see the whole tomato when I am only presented with its facing side? Because, answers the sensorimotor enactivist, I implicitly understand the regular and predictable ways in which exploratory movements would bring other aspects of the tomato into view. How can I experience the environment as rich and detailed given the limits of my sensory sensitivity? Because I understand the ways in which further details of the environment can be revealed through exploratory activity.

O'Regan (1992) thus suggests that the world itself serves as an 'outside' memory; an external information store which can be accessed as needed through exploratory movements such as saccades. Developing this idea, Noë (2004) claims that vision is analogous to reading an online version of a newspaper. Rather than downloading the entire issue at once, your computer accesses each article only when called upon, saving bandwidth and ensuring you always see the most recent version of the article. Importantly, for practical purposes this is just like having the entire edition in front of you, since you have access to it 'virtually'. Perception, he suggests, involves an analogously virtual access to environmental detail, though in a disanalogy with the newspaper case, Noë claims that perception is virtual 'all the way in', meaning perceptual experience does not break down into a locally represented and a merely virtual component, but depends in its entirety on the possession and exercise of the sensorimotor skills needed to access detail in the environment. In this way, sensorimotor enactivists endorse Brooks' anti-representationalist design strategy of using the world as its own best model, emphasising skilful capacities for accessing information over the construction and manipulation of detailed internal models.

One source of disagreement within sensorimotor enactivism concerns exactly how the sensorimotor contingencies (SMCs) used to explain perception should be understood. O'Regan and Noë (2001) present SMCs as dependencies between subpersonal effector and sensor states. The phenomenal differences between sense modalities can be accounted for, they claim, by patterns determined by the differing physical characteristics of the sense organs, while phenomenal differences within sense modalities, e.g. between different colour qualities, can be accounted for by sensorimotor patterns determined in addition by the objects interacted with. Noë (2004) shifts his emphasis to the personal level, suggesting that perceptual phenomenology is determined by relations between possible movement and the ways objects are presented from a particular perspective. For example, the circular shape of a plate is perceived in virtue of an implicit understanding of the way in which its elliptical appearance changes as a perceiver moves around it. Other forms of sensorimotor enactivism (e.g. Hurley 1998; Hurley and Noë 2003) emphasise both kinds of SMCs for different explanatory purposes. ${ }^{13}$

Because we often perceptually experience features with which we are not presently interacting or in sensory contact, sensorimotor enactivism usually claims that perception requires not only that patterns of sensorimotor dependence obtain, but also that perceivers have 'knowledge' (or 'mastery', or 'understanding') of them. Importantly, such 'sensorimotor understanding' is construed as implicit and practical, rather than explicit and propositional (see Hurley 1998 (ch. 4), Noë 2004 (ch. 6), Roberts 2010). Beyond this broad-brush characterization of the nature of sensorimotor understanding, however, there is little consensus about how this notion should be understood - and, as we will see below, some enactivists argue that this feature of the view should be dispensed with altogether. The uncertain role of knowledge in sensorimotor enactivism is reflected by the quite different ways it has been developed scientifically. While some have begun to flesh out the implementational details of sensorimotor perception by appealing to entirely non-representational dynamical systems (e.g. Buhrmann et al. 2013; Flament-Fultot 2016), others have developed the approach in a more cognitivist framework, for example Seth (2014), who has combined it with a predictive processing account, or Maye and Engel (e.g. 2016) who have

\footnotetext{
${ }^{13}$ See Ward (2016) for a reconstruction of the relationship between subpersonal and personal-level SMCs in Susan Hurley's sensorimotor enactivism.
} 
used a representational implementation of sensorimotor knowledge in robot control architectures.

There is also disagreement about the scope of sensorimotor enactivism. Noë $(2004,2016)$ is clear that the while his version of the approach is intended to shed light on the character of perceptual experience, it is not intended as an account of consciousness more generally, in part because there are pre-requisites for consciousness that fall outside the scope of sensorimotor enactivism and are to be addressed by enactivism's autopoietic variants. O'Regan (2011), by contrast, presents sensorimotor enactivism as a way of understanding consciousness more generally. Remaining in many respects indifferent to how perception is implemented, O'Regan suggests that the approach is not intended to explain the mechanics of perception, but the phenomenal qualities that feature in it. He moreover emphasises that the approach is also meant to explain the phenomenal difference between perception and others kinds of conscious and unconscious process. Perception is distinguished by bodiliness, the fact that sense inputs change when you move, insubordinateness, the fact that these changes are partly shaped by the environment, grabbiness, the fact one's attention is automatically drawn to sudden changes in sense input, and richness, the fact that the environment contains rich detail. Other sensations, such as pain, can in part be accounted for, he suggests, by the fact they lack some of these features or share them but to different degrees. Aiming to account for the very existence of consciousness, O'Regan's sensorimotor enactivism claims that perceptual consciouness requires the addition of cognitive access to what one perceives and a sense of 'self'. Explicitly rejecting apparatuses like autonomy and normativity, O'Regan's version of the approach claims that perception and consciousness so-construed could be instantiated by a machine without biological life, a topic addressed by Degenaar and O'Regan in their contribution to this volume.

The various forms of sensorimotor enactivism, then, share TEM's commitment to understanding perception in terms of capacities for perceptually-guided activity. But whereas autopoietic enactivists aim to explain a wide variety of cognitive capacities in terms of the autopoietic and adaptive dynamics sketched above, sensorimotor enactivists usually restrict their focus to perceptual experience, which is to be explained by appeal to sensorimotor dynamics relating perception to action. And while autopoietic enactivists are often committed to a Jonas-inspired deep continuity between life and mind, and a conception of perceptible qualities as enacted, rather than existing independently of the perceiver's activity, sensorimotor enactivists typically remain neutral on these phenomenological and metaphysical claims.

\subsection{Radical Enactivism}

The final brand of enactivism that has emerged since TEM's appearance is Hutto and Myin's radical enactivism, or 'Radically Enactive Cognition' (REC). ${ }^{14}$ As Hutto (this issue) emphasises, however, REC should be seen as an attempt to improve and unify anti-representationalist approaches to cognition rather than as competing with autopoietic or sensorimotor enactivism. As presented in Hutto and Myin (2013), REC takes up the general enactivist project of rejecting cognitivism in favour of analysing minds in terms of dynamic patterns of adaptive environmental interactions. Like sensorimotor enactivism, REC does not commit itself to the phenomenological and metaphysical claims of autopoietic enactivism, such as strong life/mind continuity and the claim that perceptible qualities are enacted rather than perceiver-independent.

As Hutto (this issue) puts it, REC aims to "cleanse, purify, strengthen and unify a whole set of anti-representational offerings'. These offerings include the varieties of enactivism sketched above, as well as work in dynamical systems theory, embodied robotics and Gibsonian psychology. According to REC, autopoietic and sensorimotor enactivism incur implicit commitments to the cognitivist doctrines they aim to supplant. Above, we noted that sensorimotor enactivists typically require that the sensorimotor contingencies linking perception to action must be implicitly known or understood in order to issue in genuine perception. Anti-representationalist critics of sensorimotor enactivism (e.g. Hutto and Myin 2013; Chemero 2016) take issue with this requirement for two related reasons. First, that such a mediating role for sensorimotor understanding invites cognitivist analysis in terms of internal rules and representations of sensorimotor contingencies; second, that this overintellectualises perception, understanding it in terms of cognitively sophisticated capacities that are left unanalysed by sensorimotor enactivists. REC points to embodied robotics and dynamical systems modelling as worked examples of how intelligent behaviour can emerge in the absence of internal representations and mediating knowledge or understanding of the functioning of the system.

$R E C$ also objects to (or at least heavily qualifies) autopoietic enactivism's attempts to ground intentional relations to the environment in biodynamics-for example the claim, sketched above, that adaptive regulation of autopoietic dynamics constitutes a form of sense-making that enacts meaning and significance in the organism/environment relationship. The reason for this is tied to the

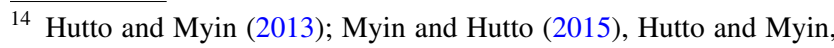
forthcoming.
} 
particular way in which REC's anti-representationalism is motivated. Hutto and Myin (2013; see also Hutto 2011; Hutto and Satne 2015) emphasise the lack of progress in providing an acceptable naturalised theory of intentional content, claiming that our best current theories of how some state or process in an organism can represent an environmental property or feature all appear to face insuperable difficulties. For example, 'teleosemantic' theories appeal to the evolutionary history of organisms and their constituent parts in order to specify the content of representational states. If a perceptual mechanism has been selected for in virtue of its capacity to detect nearby tigers and initiate a fleeing response, then its (action-oriented) content is something like: 'Tiger; flee!' A well-known problem for such views (e.g. Fodor 1990) is that an organism's evolutionary history can't always be used to disambiguate between different descriptions of what its constituent mechanisms have been selected for; for example, between 'tiger' and 'striped predator'. Whilst this kind of indeterminacy is irrelevant for natural selection, it appears damaging to the prospects of providing a theory of representational content. ${ }^{15} R E C$ emphasises such worries about teleosemantics and other attempts to naturalise representation in its case against cognitivism, and thus construes the job of enactivist cognitive science as characterising active engagements of organism and environment that support a basic but contentless form of mindedness. REC can thus agree with the autopoietic enactivist's contention that biodynamics underpin cognition, while disagreeing about the way in which those dynamics ground attributions of content (for example characterising a bacterium as aiming towards, or valuing, sucrose).

In this way, REC agrees with standard critiques of teleosemantics that representational content is underdetermined by biological function. Nonetheless, Hutto and Myin argue that the evolutionary history of an organism's capacities for adaptive interaction can ground a teleological relation between organism and environment-though one without determinate, propositionally specifiable content. Whilst such determinate content is an important part of the cognitive lives of mature humans-for example in exercising capacities for judging, reasoning, and perceiving - this determinacy is only possible in virtue of socially scaffolded practices for interpersonal understanding (Hutto 2008) and language use that bring with them an added layer of normative constraint that is a criterion for genuine content (Hutto and Satne 2015). The autopoietic enactivist's mistake, according to $R E C$, is to describe basic interactive capacities

15 These issues are, of course, controversial. See e.g. Godfrey-Smith ( 2006) and Neander (2012) for useful surveys. in terms that presuppose both a rich selective history and a complex sociocultural context.

$R E C$ thus draws on the same intellectual lineage as the above varieties of enactivism, rejecting cognitivism in favour of an emphasis on interactive dynamics. It goes beyond autopoietic and sensorimotor enactivism in its scepticism about the propriety of representational or contentful talk in characterising these dynamics, and this scepticism motivates a distinction between 'basic' cognitive capacities grounded in adaptive sensorimotor interaction and the richer socioculturally scaffolded capacities characteristic of mature human cognition. REC thus aims to analyse $\operatorname{cog}$ nition in terms of an interplay between the biological and sensorimotor dynamics emphasised by the above forms of enactivism (suitably purged of representationalist undertones) and social dynamics that bootstrap basic minds into the realm of contentful thought and experience.

\subsection{Enactivism's Extended Family}

Finally, much influential work in the philosophy of mind and cognitive science over the past 25 years has focused on developing the currents that fed into TEM in ways that overlap with the forms of enactivism summarised above, but without identifying itself as 'enactivist'. Views of the mind as embodied, embedded, extended, affective, or some combination of these, are members of the enactivist family at least in virtue of sharing important common ancestry. Attempting a taxonomy of the lines of research carried on under each of these banners is far beyond the scope of our task here (see e.g. Rowlands 2010; Shapiro 2010 for partial attempts). We can note, at least, that enactivist theories are committed to a specific conception of cognition as embodied insofar as they all ground cognition in capacities for dynamic interaction between organism and environmentsomething that is only possible for an embodied entity. In emphasising organism/environment interactions enactivists likewise commit themselves to a view of cognition as essentially embedded - to be explained not only by properties of the organism itself, but also by properties of its environment and its interactions with it. As we have seen above, different varieties of enactivism develop these themes in different ways, depending on the range of interactive dynamics to which they appeal. Autopoietic enactivists, for example, stress the way in which the fine details of an organism's embodiment determine the particular cognitive structures and relations it enacts, while sensorimotor enactivists are interested in details of embodiment only insofar as such details shape dynamic relations between sensation and movement. REC, as just noted, suggests a particular view of the socioculturally scaffolded environment in which human cognition is essentially embedded, in a way that goes beyond its autopoietic and sensorimotor siblings. 
Beyond these commonalities, however, the relationship between enactivism and other $E$-centric approaches to cognition is disputed. In particular, the view that cognition should sometimes be understood as extended - that is, as having a material substrate that includes portions of the environment as well as of the organism-enjoys an uneasy relationship with enactivism. Ironically, the hypothesis of extended cognition draws on the very same sources surveyed in Sect. 1, marshalling evidence that cognition can depend on patterns of dynamic interaction between brain, body and environment in service of the claim that cognition can constitutively depend on these interactions as a whole, rather than just on their internal effects (Clark and Chalmers 1998; Clark 2008). However, Wheeler (2008) argues that autopoietic enactivism's appeal to biodynamics that create and maintain a stable boundary between organism environment locks the processes constitutive of cognition within that boundary. In his contribution to this special issue Wheeler focuses on the relationship between extended cognition and radical enactivism. Hutto et al. (2014) argue that radical enactivism entails a form of extended cognition, since replacing a conception of cognition as essentially content-involving with the radical enactivist's emphasis on patterns of scaffolded interaction removes the temptation to construe cognition as a primarily internal process that can, in appropriate cases, extend. Instead, a relational, environment-implicating conception of the material basis of cognition becomes the default starting point. Wheeler, however, argues that this relational conception of cognition is in fact neutral as to the location of the material processes that explain cognitive capacitiesthese processes might be internally realised, but nonetheless crucially embedded within the environment-implicating dynamics to which enactivists appeal.

An alternative view of the relationship between enactivism and extended cognition is provided in Colombetti's contribution to this issue. Following Di Paolo (2009), Colombetti argues that the enactive framework permits the dynamic processes constitutive of life (and hence, for autopoietic enactivism, constitutive of cognition) to extend beyond the biological boundaries of an organism-as when, for example, aquatic insects breathe underwater by creating and exploiting trapped air bubbles. As we saw above, autopoietic enactivists hold that the biodynamics of life entail a primitive form of affectivity, in the form of a concern for persistence. Colombetti thus argues that an extended conception of life, cognition and affectivity are entailed together by autopoietic enactivism.

\section{Conclusion}

As we've seen in this introduction, enactivism draws on many influential strands from philosophy and cognitive science. Whilst the various positions surveyed above, and explored in this special issue, each weave these strands together in slightly different ways, all are united by a common commitment to understanding cognition as rooted in our engaged, bodily lives. Taken together, we hope that the papers in this special issue provide a clearer picture both of what unites, and what divides the varieties of enactivism, and of the challenges that lie ahead as enactivism enters its mid-twenties. ${ }^{16}$

Acknowledgements Mario Villalobos' contribution to this paper was supported by Performance Agreement UTA MINEDUC.

\section{References}

Barandiaran X (in press) Autonomy and enactivism: towards a theory of sensorimotor autonomous agency. Topoi, this issue

Barrett $\mathrm{N}$ (in press) The normative turn in enactive theory: an examination of its roots and implications. Topoi, this issue

Brooks RA (1991) Intelligence without representation. Artif Intell 47(1):139-159

Buhrmann T, Di Paolo EA, Barandiaran X (2013) A dynamical systems account of sensorimotor contingencies. Front Psychol 4:285

Chemero A (2011) Radical embodied cognitive science. MIT Press, Cambridge

Chemero A (2016) Sensorimotor empathy. J Conscious Stud 23(5-6): $138-152$

Clark A (1989) Microcognition: philosophy, cognitive science, and parallel distributed processing. MIT Press, Cambridge

Clark A (1993) Associative engines: connectionism, concepts, and representational change. MIT Press, Cambridge

Clark A (1997) Being there: putting brain, body, and world together again. MIT Press, Cambridge, MA

Clark A (2008) Supersizing the mind: embodiment, action, and cognitive extension. Oxford University Press

Clark A, Chalmers DJ (1998) The extended mind. Analysis 58(1):7-19

Colombetti G (in press) Enactive affectivity, extended. Topoi, this issue

Degenaar J, O’Regan JK (in press) Sensorimotor theory and enactivism. Topoi, this issue

Di Paolo E (2005) Autopoiesis, adaptivity, teleology, agency. Phenomenol Cogn Sci 4(4):429-452

Di Paolo EA (2009) Extended life. Topoi 28:9-21

Di Paolo EA, Thompson E (2014) The enactive approach. In: Shapiro L (ed) The routledge handbook of embodied cognition. Routledge Press, New York, pp 68-78

Dreyfus HL (1972) What computers can't do. Harper and Row, New York

\footnotetext{
16 The editors of this special issue would like to thank the EIDYN research centre at the University of Edinburgh, the Mind Association, and the AISB for generous funding that made the workshops from which these papers were drawn possible.
} 
Dreyfus HL (2007) Why Heideggerian AI failed and how fixing it would require making it more Heideggerian. Philos Psychol 20(2):247-268

Flament-Fultot M (2016) Counterfactuals versus constraints: towards an implementation theory of sensorimotor mastery. J Conscious Stud 23(5-6):153-176

Fodor J (1990) A theory of content. In: A theory of content and other essays. MIT Press, Cambridge

Gallagher S, Zahavi D (2013) The phenomenological mind. Routledge, Abingdon

Gibson JJ (1979). The ecological approach to visual perception. Houghton Mifflin, Boston

Godfrey-Smith P (2006) Mental representation, naturalism and teleosemantics. In: MacDonald G, Papineau D (eds) Teleosemantics. University Press, Oxford

Haugeland J (1978) The critical assessment of cognitivism: a closer look. Behav Brain Sci 2:215-260

Haugeland J (ed) (1981) Mind design. MIT Press, Cambridge

Haugeland J (2013) Dasein disclosed: John Haugeland's Heidegger. Harvard University Press, Cambridge, MA

Heidegger M (1927/1962) Being and time, trans. J. Macquarrie and E. Robinson. Basil Blackwell, Oxford

Horgan TE, Tienson JL (1992) Cognitive systems as dynamic systems. Topoi 11(1):27-43

Hurley S (1998) Consciousness in Action. MIT Press, Cambridge

Hurley S, Noë A (2003) Neural plasticity and consciousness. Biol Philos 18:131-168

Hutto D (2008) Folk psychological narratives: the sociocultural basis of understanding reasons. MIT Press, Cambridge

Hutto D (2011) Philosophy of mind's new lease on life: Autopoietic enactivism meets teleosemiotics. J Conscious Stud 18(5-6):44-64

Hutto D (in press) REC: revolution effected by clarification. Topoi, this issue

Hutto D, Myin E (2013) Radicalizing enactivism: basic minds without content. MIT Press, Cambridge

Hutto D, Myin E (forthcoming) Evolving enactivism: basic minds meet content. MIT Press, Cambridge

Hutto DD, Satne G (2015) The natural origins of content. Philosophia 43(3):521-536

Hutto DD, Kirchhoff MD, Myin E (2014) Extensive enactivism: why keep it all in? Front Hum Neurosci 8(706):1-11

Jonas H (1966) The phenomenon of life: toward a philosophical biology. Northwestern University Press, Evanston

Kaufer S, Chemero A (2015). Phenomenology: an introduction. Wiley, Hoboken

Maturana HR, Varela FJ (1980) Autopoiesis and cognition: the realization of the living. Kluwer, Dordrecht

Maye A, Engel AK (2016) The sensorimotor account of sensory consciousness: implications for machine consciousness. J Conscious Stud 23(5-6):177-202

Merleau-Ponty M (1945/2012) Phenomenology of perception. Trans. D.A. Landes. Routledge, London

Myin E, Hutto D (2015) REC: just radical enough. Stud Log Gramm Rhetor 41(1):61-71

Neander K (2012) Teleological theories of mental content. In: Zalta Edward N (ed) The Stanford encyclopedia of philosophy. https:// plato.stanford.edu/archives/spr2012/entries/content-teleological/
Noë A (2004) Action in perception. MIT Press, Cambridge MA

Noë A (2012) Varieties of presence. Harvard University Press, Cambridge, MA

Noë A (2016) Sensations and situations: a sensorimotor integrationist approach. J Conscious Stud 23(5-6):66-79

O'Regan JK (1992) Solving the "real" mysteries of visual perception: the world as an outside memory. Can J Psychol 46:461-488

O'Regan JK, Noë A (2001) A sensorimotor account of visual consciousness. Behavior Brain Sci 24:939-1031

O'Regan JK (2011) Why red doesn't sound like a bell. Explaining the feel of consciousness. Oxford University Press, Oxford

Pfeifer R, Bongard J (2006) How the body shapes the way we think: a new view of intelligence. MIT press, Cambridge

Roberts T (2010) Understanding 'Sensorimotor Understanding'. Phenomenol Cognit Sci 9(1):101-111

Rowlands, Mark (2010) The new science of the mind: from extended mind to embodied phenomenology. MIT Press, Cambridge

Seth AK (2014) A predictive processing theory of sensorimotor contingencies: explaining the puzzle of perceptual presence and its absence in synesthesia. Cognit Neurosci 5(2):97-118

Shapiro L (2010) Embodied cognition. Routledge, UK

Thompson E (2004) Life and mind: from autopoiesis to neurophenomenology. a tribute to Francisco Varela. Phenomenol Cognit Sci 3(4):381-398

Thompson E (2007) Mind in life: biology, phenomenology, and the sciences of mind. Harvard University Press, Cambridge, MA

Thompson E (2014) Waking, dreaming, being. Columbia University Press, New York

Thompson E (In press) Preface to The Embodied Mind

Thompson E, Stapleton M (2009) Making sense of sense-making: Reflections on enactive and extended mind theories. Topoi 28(1):23-30

Varela FJ (1997) Patterns of life: intertwining identity and cognition. Brain Cognit 34(1):72-87

Varela FJ, Thompson E, Rosch E (1991) The embodied mind. MIT Press, Cambridge

Villalobos M, Ward D (2016) Lived experience and cognitive science: Reappraising Enactivism's Jonasian Turn. Constr Found 11(2):204-212

Ward D (2016) Hurley's Transcendental Enactivism. J Conscious Stud 23(5-6): 12-38

Ward D, Villalobos M (2016) Authors' Response: Enactivism, cognitive science, and the Jonasian Inference. Constr Found 11(2):228-233

Weber A, Varela F (2002) Life after kant: natural purposes and the autopoietic foundations of biological individuality. Phenomenol Cogn Sci 1:97-125

Wheeler M (2008) Mind, things and materiality. In: Renfrew C, Malafouris L (eds) The cognitive life of things: recasting the boundaries of the mind. McDonald Institute for Archaeological Research Publications, Cambridge

Wheeler M (in press) The revolution will not be optimised: Radical enactivism, extended functionalism and the extensive mind. Topoi, this issue. 